Review of Progress in

QUANTITATIVE

NONDESTRUCTIVE

EVALUATION

Volume 17A 
A Continuation Order Plan is available for this series. A continuation order will bring delivery of each new volume immediately upon publication. Volumes are billed only upon actual shipment. For further information please contact the publisher. 


\section{Review of Progress in}

QUANTITATIVE

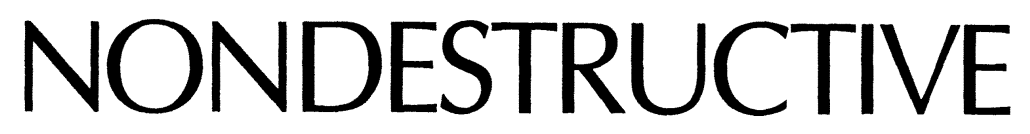

\section{EVALUATION}

\section{Volume 17A}

Edited by

Donald O. Thompson

Center for NDE

Ames Laboratory (USDOE)

and Department of Aerospace Engineering and Engineering Mechanics

lowa State University

Ames, lowa

and

Dale E. Chimenti

\section{Center for NDE}

and Department of Aerospace Engineering and Engineering Mechanics lowa State University

Ames, lowa 
The Library of Congress has cataloged earlier volumes of this title as follows:

Library of Congress Cataloging in Publication Data

Main entry under title:

Review of progress in quantitative nondestructive evaluation.

"Proceedings of the Eighth Air Force/Defense Advanced Research Projects Agency Symposium on Quantitative Nondestructive Evaluation, held August 2-7, 1981, at the University of Colorado, Boulder" — Vol. 1, verso t.p.

"First half of the proceedings of the ninth review of progress in quantitative nondestructive evaluation, held August 1-6, 1982, at the University of California, San Diego, California" - Vol. $2 A$, t.p. verso.

"Proceedings of the Tenth Annual Review of Progress in Quantitative Nondestructive Evaluation, held August 7-12,1983, at the University of California, Santa Cruz,

California"-Vol. 3, verso CIP t.p.

Includes bibliographical references and index.

1. Nondestructive testing-Congresses. I. Thompson, Donald O. II Chimenti, Dale E. III. United States. Air Force. IV. Air Force/Defense Advanced Research Projects Agency Symposium on Quantitative Nondestructive Evaluation (8th: 1981: University of Colorado, Boulder) V. United States. Defense Advanced Research Projects Agency.

ISBN 978-1-4613-7436-7 ISBN 978-1-4615-5339-7 (eBook)

DOI $10.1007 / 978-1-4615-8291-5$

First half of the proceedings of the Twenty-Fourth Annual Symposium on Quantitative Nondestructive Evaluation, held July 27-August 1, 1997, in San Diego, California

C 1998 Plenum Press, New York

Softcover reprint of the hardcover 1st edition 1998

A Division of Plenum Publishing Corporation

233 Spring Street, New York, N.Y. 10013

http://www.plenum.com

10987654321

All rights reserved

No part of this book may be reproduced, stored in a retrieval system, or transmitted in any form or by any means, electronic, mechanical, photocopying, microfilming, recording, or otherwise, without written permission from the Publisher 


\section{PREFACE}

These Proceedings, consisting of Parts A and B, contain the edited versions of most of the papers presented at the annual Review of Progress in Quantitative Nondestructive Evaluation held at University of San Diego, San Diego, CA, on July 27 to August 1, 1997. The Review was organized by the Center for NDE at Iowa State University, in cooperation with the Ames Laboratory of the USDOE, the American Society of Nondestructive Testing, the National Institute of Standards and Technology, the Federal Aviation Administration, and the National Science Foundation Industry/University Cooperative Research Centers.

This year's Review of Progress in QNDE was attended by approximately 370 participants from the US and many foreign countries who presented a total of approximately 350 papers. As usual, the meeting was divided into 36 sessions with four sessions running concurrently. The Review covered all phases of NDE research and development from fundamental investigations to engineering applications and inspection systems, and methods of inspection science from acoustics to x-rays. The Review continues to experience some fluctuations in size, mostly under pressure from a decrease in funding for NDE research at the US Federal level, but increased participation from foreign laboratories has more than made up the difference. The Review is ideally sized to permit a full-scale overview of the latest developments in a collegial atmosphere that most participants favor.

The opening plenary session this year concentrated on advances in imaging technologies and methodologies that have been made in recent years. Dr. K. Wickramsinghe of the IBM T. J. Watson Research Center discussed advances in scanning probe microscopy that have been made in recent years. Special attention was given to a discussion of the scanning tunneling microscope (STM) and the atomic force microscope (AFM). Dr. Wickramsinghe has made many important contributions to QNDE in the past. It was indeed a pleasure to welcome him back as the keynote speaker. Professor James Oliver of Iowa State University and Dr. William Green of the Jet Propulsion Laboratory at the California Institute of Technology completed the Plenary Sessions with overview papers on interactive visual supercomputing and digital processing of remotely sensed imagery. Prof. Oliver's talk highlighted recent advances in the use of virtual reality as an interface tool to explore results of simulations. Dr. Green provided an excellent discussion of digital processing technologies and provided an extremely timely highlight in the form of images from the Mars Pathfinder mission.

One of the traditions of the QNDE review is the Wednesday evening special session, a session that is designed to focus attention on current events that may influence research and development activity in NDE. This year's invited speaker was Mr. Tobey M. Cordell, NDE Branch Chief, Metals, Ceramics, and NDE Divisions at the Wright Laboratory. In his talk, "NDE: A Full Spectrum Technology," Mr. Cordell discussed Air Force NDE activities that 
extend through and include all elements of the use cycle of military aircraft. It was followed by a period of active discussion.

Following a pattern set about ten years ago, the Proceedings are structured to reflect the organization of the Review itself, making chapters and papers easier to find. Arrangement of papers into topical subject headings follows a plan now familiar to regular attendees of the Review. As always, some minor changes in the headings and their subcategories need to be introduced to accommodate the evolution of the field and the specific contributed items in any particular year. The Contents contain subject areas which reflect the current activity in NDE. In the following paragraphs we offer a brief summary of the research presented in the two parts.

The leading paper in the initial, highlighted Special Topics section, "Fatigue Damage and its Nondestructive Evaluation: An Overview," is a tribute to our dear friend and colleague, Professor Otto Buck of Iowa State University. Otto participated in the 1997 Review in its entirety and delivered the above paper himself, a review of research he and others have conducted in this area over the past 25 years. Last November, Otto lost his battle with pancreatic cancer, a deadly disease he faced with grace, wit, and courage. Otto will be sorely missed as a friend and fellow scientist. His work in metal fatigue, ultrasonic harmonic generation, and other areas in which he was active over the past 37 years, is held in high regard by the materials and NDE communities. Dr. Green's paper on imagery (including some very recent Mass imaging) is also included in the Special Topics. This was indeed a timely talk, and coincided with the early portion of the Mars Mission. Also part of this special section is a talk given on Tuesday from Dr. E. G. Jablonski, a physician with Molecular Biosystems, Inc. of San Diego on "Ultrasound Contrast Agents: The Advantage of Albumin Microsphere Technology." His talk was part of a biomedical session the Review has sponsored in recent years to foster the connection between biomedical and inspection sciences featuring noninvasive measurements.

Parts A and B follow the Special Topics section. As we have done in earlier volumes, Part A of the Review treats subjects related to technique development, whereas Part B is dedicated to the theme of materials. Topics such as elastic waves, guided waves, and eddy current detection, inversion, and modeling can be found in Part A. Radiography and computed tomography, thermal techniques, and acoustic emission are also included. Emerging technologies such as laser ultrasonics, optical methods, and microwaves form Chapter 2. Signal processing and image analysis and reconstruction, with an emphasis on interpretation for defect detection, come next. Chapter 4 on NDE Sensors and Fields, both ultrasonic and electromagnetic, closes Part A of the Review. In Part B are collected papers on engineered materials, materials characterization, and NDE systems. In the contributed papers of Chapter 5, composites coatings and films, and bonded joints are covered. The next chapter, on material characterization, includes sections on properties, construction materials, cracks, and residual stress and texture. This is one of the longest chapters in the Review and amply demonstrates the strong synergistic relationship between NDE and materials science. Two further chapters deal with important emerging application areas of new inspection procedures and process control. The last chapter also includes papers on new systems and techniques, and questions associated with NDE education.

The organizers of the Review wish to acknowledge the assistance of the many individuals whose efforts and participation helped to make this year's Review a success. They are indebted to the guest speakers for the opening Plenary and the Wednesday evening discussion sessions. A number of people from various institutions helped in the organization of special sessions. They include M. Gorman (Digital Wave Corporation), M. 
Holland (Washington University, St. Louis), J. Moulder (Iowa State University), P. Nagy (University of Cincinnati), H. Ringermacher (General Electric Corp.), S. Rohklin (Ohio State University), R. Thomas (Wayne State University), S. Udpa (Iowa State University), and R. Zoughi (Colorado State University). The organizers are indebted to the many chairpersons for managing and keeping sessions on time yet finding room for key points of technical discussion. They are indebeted to Ms. Linda Poore, Ms. Judy Johnson, Ms. Libby Bilyeu, and Ms. Heidi Clinton for their assistance both prior to and at the meeting, and to Ms. Karen Cheney and Ms. Joann Wallace of Summit Associates, Inc., for their management of conference logistics. The organizers are deeply indebted to Ms. Connie Nessa and Ms. Sarah Kallsen for their devoted dedication and highly professional attention to the preparation of meeting materials especially the careful handling of all abstracts and manuscripts for the Proceedings. Finally, and by no means last, the organizers appreciate the support and contributions of the Review attendees both in their presentations and prepared manuscripts without which these volumes would be impossible.

Donald O. Thompson

Emeritus Director, Center for NDE and

Anston Marston Distinguished Professor, Aerospace Engineering and Engineering Mechanics Iowa State University Ames, IA 50011

Dale E. Chimenti

Center for NDE and Department of Aerospace Engineering and Engineering Mechanics Iowa State University Ames, IA 50011

Note added in proof:

It is with heartfelt sadness that we note the untimely passing of Mr. John Charles Moulder, Center for NDE and Iowa State University, on January 19, 1998. John, a leading contributor in eddy current research, will be sorely missed by friends and colleagues alike. We wish to pay tribute to John for his many lasting contributions to science and technology. 
CONTENTS

\section{VOLUME 17A}

\section{SPECIAL TOPICS}

Fatigue Damage and Its Nondestructive Evaluation: An Overview $\ldots \ldots \ldots \ldots \ldots . \quad 1$ O. Buck

Ultrasound Contrast Agents: The Advantage of Albumin Microsphere Technology . . 15

E. G. Jablonski, H. C. Dittrich, J. M. Bartlett, and S. B. Podell

Digital Processing of Remotely Sensed Imagery $\ldots \ldots \ldots \ldots \ldots \ldots \ldots \ldots \ldots . \ldots \ldots$

W. B. Green, D. Jensen, and A. Culver

\section{CHAPTER 1. STANDARD TECHNIQUES}

\section{Section A. Elastic Wave Scattering/Backscattering}

Multiple Scattering Calculations by Born Series Integral Equations $\ldots \ldots \ldots \ldots \ldots 33$ M. Kitahara and K. Nakagawa

Acoustic Response of a Layer of Spherical Inclusions with a Random or Periodic

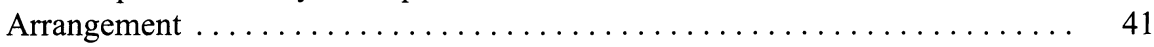

V. K. Kinra, K. Maslov, B. K. Henderson, and G. Diderich

Coherent Reflection and Transmission by a Randomly Cracked Elastic Slab . . . . . 49 Y. C. Angel and A. Bolshakov

Theoretical Evaluation of Ultrasonic Scattering by Flaws in Anisotropic Media . . . . 57 M. Spies and M. Kröning

Elastic Wave Scattering from a Rough Strip-Like Crack $\ldots \ldots \ldots \ldots \ldots \ldots \ldots$ P. Å. Jansson

SH Wave Scattering by a Defect in a Plate $\ldots \ldots \ldots \ldots \ldots \ldots \ldots \ldots \ldots \ldots \ldots \ldots$

S. Hirose

A 2D Hybrid Model for Ultrasonic Pulse-Echo Scattering from a Rough Interface Buried in a Layered Medium . . . . . . . . . . . . . . . . . . . . . 81

S. Zeroug and Y.-H. Chen 
Use of Electron Backscatter Diffraction in Understanding Texture and the

Mechanisms of Backscattered Noise Generation in Titanium Alloys . . . . . . . .

P. D. Panetta, R. B. Thompson, and F. J. Margetan

The Application of Angular Profile of Ultrasonic Backscattering on the Layered

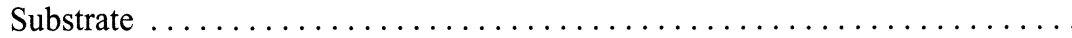

S. D. Kwon, D. J. Yoon, and B. Y. Ahn

Use of Rician Distributions to Predict the Distributions of Ultrasonic Flaw Signals in the Presence of Backscattered Noise

I. Yalda, F. J. Margetan, and R. B. Thompson

\section{Section B. Guided Waves and Applications}

Characteristics of the Reflection of Lamb Waves from Defects in Plates and Pipes . . 113 M. Lowe

Wave Propagation in a Plate with Defects

Z. Chang and A. Mal

Effect of Rough Surfaces on Guided Waves in Plates

D. E. Chimenti and O. I. Lobkis

Geometrical Acoustics in a Heterogeneous Anisotropic Elastic Solid: Application to a Wavy Composite

K. Y. Kim, W. Zou, and W. Sachse

Effects of a Flaw on Acoustic Wave Propagation by an EMAT System ...........

T. Sugiura and S. Maruyama

Guided Transient Waves in a Circular Annulus

G. Liu and J. Qu

Application of Finite Element Methods to Study Transient Wave Propagation in

Elastic Wave Guides

F. Moser, L. J. Jacobs, and J. Qu

Experimental Observation of the Slow Squirting Mode in Solid/Fluid/Solid

Trilayers

W. Hassan and P. B. Nagy

Characterization of Piezoelectrics Using Line-Focus Transducer .

C.-H. Yang

Calculation of Dispersion Curves in Bonded Joints Using Either Complex

Frequency or Complex Slowness and Comparison of the Results with the

Minima of the Plane Wave Reflection Coefficients

A. Bernard, M. Lowe, and M. Deschamps

An Experimental Study of Crack Detection in Annular Components by Ultrasonic

Guided Waves

Z. Li and Y. H. Berthelot 


\section{Section C. Eddy Currents}

Modeling Eddy Current Crack Signals of Differential and Reflection Probes 209

N. Nakagawa, K. Dasoju, T. A. Khan, and J. C. Moulder

Eddy Current Scan Simulation with Coupled FEM/BEM

E. A. Creek and R. E. Beissner

Recent Development of MESSINE, a 3D Eddy Current Model

R. La, B. de Barmon, B. Benoist, M. Talvard, R. Lengellé, and P. Gaillard

Mathematical Modeling of the Interaction of Non-Uniform Field ACFM with Finite Size Cracks . . . . . . . . . . . . . . . . . . . . . . . . . . . . . . . . . . . . 229

R. Mostafavi and D. Mirshekar-Syahkal

Review of High Sensitivity AC Field Measurement—Recent Advances and Future Work

D. Mirshekar-Syahkal

Scaling Relation for the Inductance of a Coil on a Ferromagnetic Half-Space . . . . .

J. H. Rose, C.-C. Tai, and J. C. Moulder

Pulsed Eddy-Current Measurements for the Characterization of Thin Layers and Surface Treatments ...

M. J. Johnson and J. R. Bowler

Finite Element Simulation of Pulsed Remote Field Eddy Current Phenomenon . . . . . 259

Y. Sun, W.-C. Loo, D. C. Kunerth, and T. K. O'Brien

Theoretical Aspects of Transient Electromagnetic Field in Finite Sized Conducting

Media

M. Namkung, B. Wincheski, J. P. Fulton, and S. Nath

Optimization of a Wide-Field Eddy Current Probe Using a Boundary Element

Method Based Model

J. M. Amos and J. C. Chao

Computer Modeling of Eddy Current Transmit-Receive Probes for Tube Inspection . .

S. P. Sullivan, V. S. Cecco, L. S. Obrutsky, D. Humphrey, S. P. Smith, and

K. A. Emde

Low Frequency, Pulsed Eddy Currents for Deep Penetration

W. W. Ward III and J. C. Moulder

Rotating Excitation Probes for Inspecting PWR SG Tubes

H. Schepens, M. Pigeon, B. Benoist, J. Reuchet, and D. Boulanger

Transient Eddy-Current NDE for Hidden Corrosion in Multilayer Structures

S. K. Burke, G. R. Hugo, and D. J. Harrison 
Quantitative Assessment of Corrosion in Aircraft Structures Using Scanning Pulsed

Eddy Current . . . . . . . . . . . . . . . . . . . . . . . . . . . . . . 315

J. A. Bieber, C.-C. Tai, and J. C. Moulder

Integrating a Stress Corrosion Crack Model into Finite Element Electromagnetic

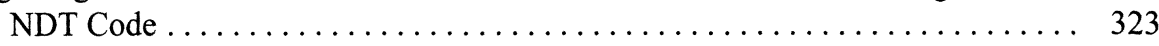

G. Kobidze, W. Lord, and S. Udpa

Detection of Sublayer Fatigue Cracks under Airframe Rivets

B. Wincheski and M. Namkung

Characterization of Mechanical Damage in Gas Transmission Pipelines

V. Kamat, C. Yeoh, P. Ivanov, D. Kim, Y. Sun, S. Mandayam, L. Udpa, S. Udpa, and W. Lord

Eddy Current Evaluation of Flaws in Coated Conductors

A. Ptchelintsev, B. de Halleux, and D. Degreve

Eddy Current Imaging Using Multi-Frequency Mixing Methods for Aircraft

Structural Integrity Verification

B. A. Lepine

\section{Section D. X-Rays and Computed Tomography}

Quantitative X-Ray Inspection

F. Retraint, J. M. Dinten, R. Campagnolo, and F. Peyrin

Radiographic Least Squares Fitting Technique Accurately Measures Dimensions and X-Ray Attenuation . . . . . . . . . . . . . . . . . . . . .

T. A. Kelley and D. M. Stupin

Status and Future Aspects of X-Ray Backscatter Imaging

W. Niemann and S. Zahorodny

SINDBAD: From Cad Model to Synthetic Radiographs

A. Glière

COBRA: Cone Beam Computed Tomography (CT) Reconstruction Code in

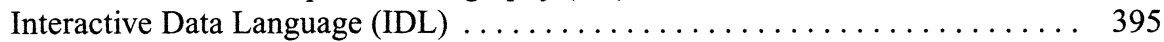

M. J. Sheats and D. M. Stupin

Limited Projection 3D X-Ray Tomography Using the Maximum Entropy Method . . 403 V. L. Vengrinovich, Y. B. Denkevich, and G.-R. Tillack

Dimensional Accuracy in X-Ray Computed Tomography Imaging

S. T. Neel, R. Gibson, C. R. Daniels, and E. L. Klosterman

Multi-Modality 3D Visualization of Hard-Alpha in Titanium Billets Utilizing CT

X-Ray and Ultrasonic Imaging $\ldots \ldots \ldots \ldots \ldots \ldots \ldots \ldots \ldots \ldots \ldots \ldots \ldots \ldots \ldots \ldots$

M. Bashyam and U. Suh

\section{Section E. Thermal Wave Imaging}

Towards a Flat-Bottom Hole Standard for Thermal Imaging $\ldots \ldots \ldots \ldots \ldots \ldots$

H. I. Ringermacher, D. J. Mayton, D. R. Howard, and B. N. Cassenti 
K. E. Cramer and W. P. Winfree

Enhanced Thermographic Detection of Delaminations with Computational Pulse

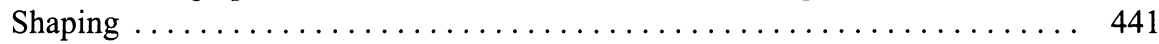

W. P. Winfree

NDE of Corrosion and Disbonding on Aircraft Using Thermal Wave Imaging . . . . .

X. Han, L. D. Favro, T. Ahmed, Z. Ouyang, L. Wang, X. Wang, P. K. Kuo, and R. L. Thomas

Novel Measurement of Anisotropic Thermal Diffusivity

Z. Ouyang, F. Zhang, L. Wang, L. D. Favro, and R. L. Thomas

Thermographic Imaging of Defects in Anisotropic Composites

Y. A. Plotnikov and W. P. Winfree

Infrared Imaging of a Stress-Crazed Polymer

Y. Wang, S. A. Telenkov, Y. Lu, L. D. Favro, P. K. Kuo, and R. L. Thomas

Application of a Generalized Methodology for Quantitative Thermal Diffusivity

Depth Profile Reconstruction in Manufactured Inhomogeneous Steel-Based

Materials

M. Munidasa, F. Funak, and A. Mandelis

Theoretical Study for Detection of Defects in Weakly Absorbing Samples by

Crossed-Beam Photothermal Technique

B.-C. Li and S.-Y. Zhang

\section{Section F. Acoustic Emission and Applications}

Rapid Calculation of Lamb Waves in Plates Due to Localized Sources . . . . . . . . 485

D. Guo and A. Mal

Application of Mindlin Plate Theory to Analysis of Acoustic Emission Waveforms

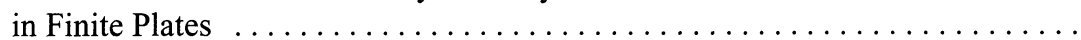

W. Huang

The Role of Propagation Characteristics in Acoustic Emission Pipeline Leak

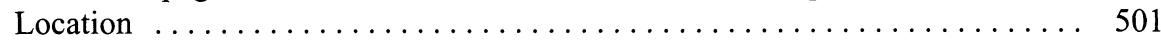

L. E. Rewerts, R. A. Roberts, and M. A. Clark

A Comparison of AE Measurements from Aluminum Alloys and Glass/Epoxy Composites with Different AE Techniques

S. H. Carpenter and M. R. Gorman

Waveform-Based Analysis of Acoustic Emission from Fiber Fracture in Model

Composite Plates

T. Bidlingmaier, A. Wanner, and S. Ritter

Two Dimensional Dislocation Sources in Fiber Composite Laminates 525

E. R. Green 
E. R. Green

Hydroproof Acoustic Emission for Prediction of Failure Behavior in Composite

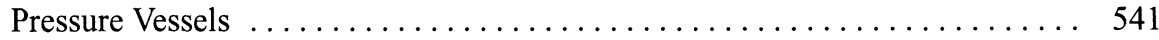

S.-J. Song, C.-H. Oh, H.-J. Kim, and J.-U. Choe

Acoustic Emission Characterization of Single and Dual Fiber Reinforced Metal

Matrix Composites ............................... 549

J.-H. Lee and W.-J. Sung

Progress in Detecting Transverse Matrix Cracking Using Modal Acoustic Emission . . 557

M. R. Gorman

Characterization of Acoustic Emission Waveforms from Fracture Events . . . . . . 565

Z. Shi, M. Koutsak, S. Bair, J. Jarzynski, and L. J. Jacobs

An Acoustic Emission Evaluation of Environmentally Assisted Cracking of

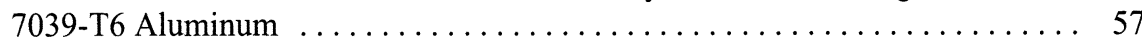

P. F. Buckley, K. Baldwin, M. J. Ehrlich, and J. W. Wagner

Analysis of Acoustic Emission Output from Propagating Fatigue Crack

I. M. Daniel, C. G. Sifniotopoulos, and J.-J. Luo

\section{CHAPTER 2. EMERGING TECHNOLOGIES}

\section{Section A. Laser/Optical Ultrasonics}

Affordable NDE of Aerospace Composites with Laser Ultrasonics

T. E. Drake, Jr., K. R. Yawn, S. Y. Chuang, and M. A. Osterkamp

Laser-Based Ultrasonic Inspection of Complexly Contoured Rocket Engine

Components ................................ 595

A. D. W. McKie and R. C. Addison, Jr.

Laser Ultrasound Imaging of Lamb Waves in Thin Plates $\ldots \ldots \ldots \ldots \ldots \ldots \ldots$

P. W. Lorraine

SAFT Data Processing Applied to Laser-Ultrasonic Inspection $\ldots \ldots \ldots \ldots \ldots \ldots 611$

A. Blouin, D. Lévesque, C. Néron, F. Enguehard, D. Drolet, and J.-P. Monchalin

Thermoelastic and Ablative Generation of Ultrasound: Source Effects

T. W. Murray and J. W. Wagner

Characterization of the Photo-emf Response for Laser-Based Ultrasonic Sensing

Under Simulated Industrial Conditions $\ldots \ldots \ldots \ldots \ldots \ldots \ldots \ldots \ldots$

D. M. Pepper, G. J. Dunning, M. P. Chiao, T. R. O’Meara, P. V. Mitchell,

I. Lahiri, and D. D. Nolte 
Ultrasonic NDE of Composite Panels with Gas-Coupled Laser Acoustic Detection .. 635 J. N. Caron, J. B. Mehl, and K. V. Steiner

A New Concept for a Laser-Based Ultrasonic Phased Array Receiver Using

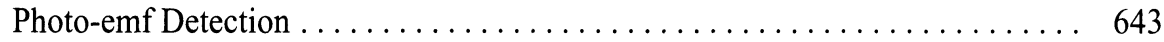

D. M. Pepper, T. R. O’Meara, and G. J. Dunning

Laser Ultrasonics NDE of Two-Layered Samples . . . . . . . . . . . . . . 651

R. Coulette, E. Lafond, F. Lepoutre, D. Balageas, M.-H. Nadal, and C. Gondard

Numerical Methods for Computing Laser Generated Ultrasound Waves . . . . . . . . 659

T. Sanderson, C. Ume, J. Jarzynski, and M. Stallybrass

Finite Element Modeling of Ultrasonic Waves Produced by a Pulsed Laser . . . . . 667 J. J. Dike

Characterization of Laser Ultrasonic Sources Using a Sagnac Interferometer . . . . . 675

P. A. Fomitchov, A. Kromine, S. Krishnaswamy, and J. D. Achenbach

Analysis of Intensity Modulated Pulse Train Length for Laser Ultrasonic NDT . . . . 683

T. Sanderson, C. Ume, and J. Jarzynski

Ultrasound Generation in Composites via Embedded Optical Fibers . . . . . . . . . 691

D. L. Balageas, N. Jaroslavsky, M. Dupont, F. Lepoutre, J.-C. Gonthier, and

L. Bertrand

\section{Section B. Microwaves}

Microwave Scattering for the Characterization of a Disc-Shape Void in Dielectric

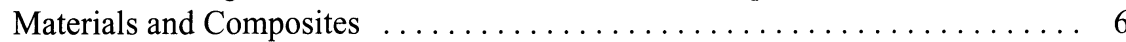

J. M. Liu

A Multi-Mode Solution for Analysis of the Reflection Coefficient of Open-Ended Rectangular Waveguides Radiating into a Dielectric Infinite Half-Space . . . . . . 705

K. Bois, A. Benally, and R. Zoughi

Development and Testing of the Time-Domain Microwave Nondestructive

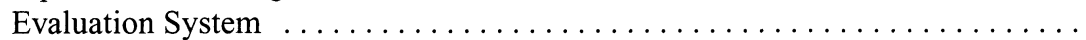

F.-C. Chen and W. C. Chew

\section{CHAPTER 3. SIGNAL PROCESSING AND IMAGE ANALYSIS}

\section{Section A. Signal Processing}

Ultrasonic Analysis of Damage Development in Polymer Composites by Signal

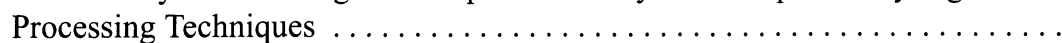

J. Stanullo, G. Busse, S. Bojinski, N. Gold, and S. Shapiro

Ultrasonic Signal Processing Applied to Flaw Characterization in Composite

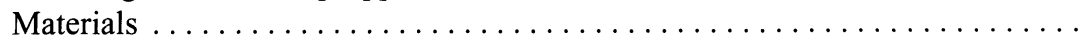

S. Alatissière, A. Liot, F. Thevenot, M. Dessendre, H. Trétout 
Time Scaling and Frequency Invariant Multiresolution Analysis of Ultrasonic NDE

Signals . . . . . . . . . . 743

R. Polikar, L. Udpa, S. S. Udpa, and J. Spanner

Artmap Networks for Classification of Ultrasonic Weld Inspection Signals

P. Ramuhalli, L. Udpa, S. S. Udpa, and J. Spanner

A New Adaptive Grain Noise Cancellation Filtering Technique

S. Bae, J. Kim, L. Udpa, and S. S. Udpa

Case-Based Reasoning for Automatic Interpretation of Data from Eddy-Current

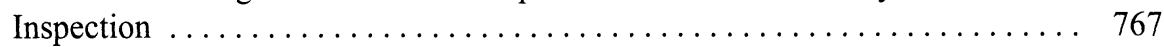

J. Jarmulak

The Application of Wavelets and Fuzzy Logic to Eddy Current Flaw Detection in Steam Generator Tubes

S.-F. Chuang, J. P. Basart, and J. C. Moulder

Shape Estimation of Defects on Steam Generator Tubes

K. Shiraishi, M. Izumida, and K. Murakami

\section{Section B. Imaging and Reconstruction}

Linear and Nonlinear Image Restoration Methods for Eddy Current Nondestructive

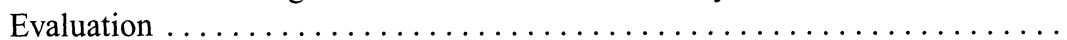

B. Wang, J. P. Basart, and J. C. Moulder

Clear Eddy Current Flaw Image Using Computerized Tomography Inversion

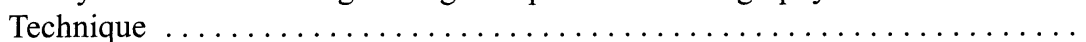

H. Hoshikawa and K. Koyama

A Homomorphic Deconvolution Technique for Improved Ultrasonic Imaging of

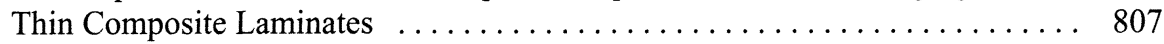

S.-C. Wooh and C. Wei

A Two-Step Inverse Procedure for Outer Surface Defects Characterization from Ultrasonic BScan Images

M. Faur, L. Paradis, and P. Morisseau

Development of Geometrical Models of Hard-Alpha Inclusions for Ultrasonic Analysis in Titanium Alloys .

B. Boyd, C.-P. Chiou, B. Thompson, and J. Oliver

Direct Numerical Approach for Analyzing Thermal Wave Interferometry Data ....

M. Oksanen

Using Complementary Types of Data for 3D Flaw Imaging

S. Gautier, B. Lavayssière, E. Fleuet, and J. Idier 


\section{CHAPTER 4. NDE SENSORS AND FIELDS}

\section{Section A. UT Sensors, Transducers, and Fields}

An Embedded Ultrasonic Wire Waveguide Sensor for In-Process Cure and

In-Service Dynamic Response Monitoring of Liquid Molded Composite Parts . . 845

Y. Li, S. M. Menon, and G. J. Posakony

Sensor Development for High Temperature Viscosity Measurement . . . . . . . . . . . 853

V. Shah, K. Balasubramaniam, R. D. Costley, and J. P. Singh

Torsional Waveguide Sensor for Molten Materials . . . . . . . . . . . . . . . . . . 859

R. D. Costley, K. Balasubramaniam, W. M. Ingham, J. A. Simpson, and V. Shah

Three Ultrasonic Devices for the Elastic Moduli Determination at High

Temperatures ................................... 867

C. Gondard, M.-H. Nadal, and C. Hermerel

Periodic Composite Backing Filter for the Design of Ultrasonic Transducers . . . . . 875

S. Chakraborty and B. DeFacio

Optimization of Ultrasonic Phased Arrays $\ldots \ldots \ldots \ldots \ldots \ldots \ldots \ldots \ldots \ldots . \ldots 83$

S.-C. Wooh and Y. Shi

Electromechanical Modeling of Ultrasonic Transducers . . . . . . . . . . . . 891

L. W. Schmerr, Jr., C. Dang, and A. Sedov

Calculation of Wideband Ultrasonic Fields Radiated by Water-Coupled Transducers into Anisotropic Media

N. Gengembre, A. Lhémery, and P. Calmon

Reconstruction of a Piston Transducer Beam Using Multi-Gaussian Beams (MGB) and Its Applications . . . . . . . . . . . . . . . . . . . . . . . . . . . . . 907

A. Minachi, F. J. Margetan, and R. B. Thompson

The Use of Huygens' Principle to Model the Acoustic Field from Interdigital Lamb

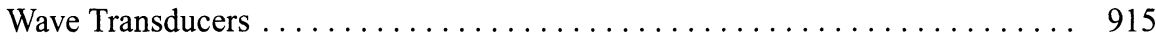

P. Wilcox, R. Monkhouse, M. Lowe, and P. Cawley

Ultrasonic Transducer Radiation through a Curved Fluid-Solid Interface . . . . . . . 923

T. P. Lerch, L. W. Schmerr, Jr., and A. Sedov

Using CAD Models in Transient Field Calculations through Arbitrarily Curved Surfaces .................................... 931

A. Schumm

Uniform Evaluation of the Four Dimensional Transducer Transmission Phase

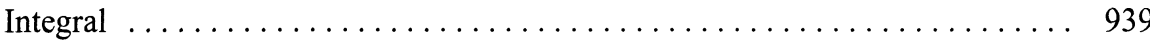

R. A. Roberts

Forward Modeling of Transducer Misalignment Effects in Ultrasonic Leaky Wave

Measurements

S. Zeroug, H. Zhang, and D. E. Chimenti 
New Developments in Ultrasonic NDT Modeling in CIVA . . . . . . . . . 955

A. Lhémery, P. Calmon, R. Raillon, and L. Paradis

Spurious Modes in Finite Element Models for Ultrasonic Waves in Fluid-Solid

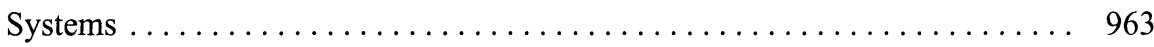

P. Stucky and W. Lord

Simulation of Ultrasound Propagation across Interfaces with Imperfect Contact 971

N. K. Batra, R. B. Mignogna, R. S. Schechter, P. P. Delsanto, E. Ruffino, and M. Scalerandi

Material Parameter Determination from Time-Domain Signals Transmitted and Reflected by a Layered Structure . . . . . . . . . . . . . . . . . . . . . . . . 979

A. Cheng

Evaluation of Dispersion Modes for Layered Structures Using Focused Acoustic Waves ......................................... 987

W.-J. Xu and M. Ourak

Finite Element Simulation of Leaky Surface Wave Propagation Excited by a

Line-Focused Transducer . . . . . . . . . . . . . . . . . . . . . . . . . . 995

K. Kawashima, T. Ito, and K. Mori

Simulation of Lamb Wave Propagation Using Pure Mode Excitation . . . . . . . . . 1003

B. Pavlakovic, D. Alleyne, M. Lowe, and P. Cawley

\section{Section B. Electromagnetic Sensors}

Boundary Integral Equations for Modeling Arbitrary Flaw Geometries in Electric Current Injection NDE . . . . . . . . . . . . . . . . . . . 1011 A. P. Ewing, C. H. Barbosa, T. A. Cruse, A. C. Bruno, and J. P. Wikswo, Jr.

Electromagnetic Microscope for Low Frequency, Pulsed, Eddy Current Evaluation of Airframes . . . . . . . . . . . . . . . . . . . . . . . . . . 1017 W. Podney

Response Function of an Electromagnetic Microscope . . . . . . . . . . . . 1025 W. Podney

New Electromagnetic Sensors for Detection of Subsurface Cracking and Corrosion . 1033 E. S. Boltz and T. C. Tiernan

Detection of Deep Flaws in Aluminum Structure with Magneto-Resistive Sensors . 1039 W. F. Avrin and R. D. Rempt

New Capacitive-Array Sensors for Post-Process Cure Verification and NDE of Polymers and Composites

E. S. Boltz, T. C. Tiernan, and W. F. Hartman

A Modified Differential Pickup Reflection Probe

S. Sharma, L. Udpa, Y. Sun, and S. S. Udpa

Uniform Eddy Current Probe with Little Disrupting Noise 1059

H. Hoshikawa and K. Koyama 
Y. P. Ma and J. P. Wikswo, Jr.

HTS SQUID System for Eddy Current Testing of Airplane Wheels and Rivets . . . 1075

H. Grüneklee, H.-J. Krause, R. Hohmann, M. Maus, D. Lomparski, M. Banzet, J. Schubert, W. Zander, Y. Zhang, W. Wolf, H. Bousack, A. I. Braginski, and M. I. Faley

A SQUID NDE Measurement Model Using Bem

A. P. Ewing, T. A. Cruse, and J. P. Wikswo, Jr.

Measurements of Surface-Breaking Flaws in Steel Pipes Using a SQUID

Susceptometer in an Unshielded Environment . . . . . . . . . . . . . 1091

C. H. Barbosa, A. C. Bruno, G. S. Kühner, J. P. Wikso, Jr., A. P. Ewing, Y. P. Ma, and C. S. Carmerini

\section{VOLUME 17B}

\section{SPECIAL TOPIC}

NDE: A Full Spectrum Technology . . . . . . . . . . . . . . . . . . . . . . . . 1099

T. Cordell

\section{CHAPTER 5. ENGINEERED MATERIALS}

\section{Section A. Composites}

Acoustic Tomographic Reconstruction of Fiber Angle in Orthotropic Composite

Materials ... . . . . . . . . . . . . . . . . . . . . . . . . . . . . . . . . . . . . 1109

C. Sullivan, R. A. Kline, and R. B. Mignogna

Identification of Viscoelastic Moduli of Composite Materials from the Plate

Transmission Coefficients .......................... 1117

B. Hosten, M. Castaings, and T. Kundu

Measurement of Anisotropic Elastic Constants of an Aluminum Composite Plate

Using a Double Reflection Method ...................... 1125

K. Kawashima, Y. Shimizu, and M. Imuta

Load-Induced Change in the Elastic Symmetry of a Ceramic Matrix Composite

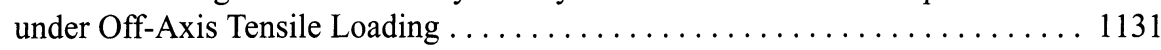

C. Aristégui and S. Baste

In-Plane Elastic Property Characterization in Composite Plates . . . . . . . . . . . . 1139

O. I. Lobkis, D. E. Chimenti, H. Zhang, and M. Rudolph

Characterization of the Ply Boundaries in Carbone-Epoxy Composite Materials

Using Longitudinal Ultrasonic Waves . . . . . . . . . . . . . . . . . 1147

M. Ourak, M. Ouaftouh, M. Duquennoy, and W. Xu 
Efficient Reconstruction of Elastic Stiffnesses in Isotropic and Anisotropic Plates . . 1155

M. Rudolph, O. I. Lobkis, and D. E. Chimenti

Elastic Wavefield Modeling for Arbitrarily Oriented Orthotropic Media . . . . . . . 1163

M. Spies and M. Kröning

Rapid Characterization of the Degradation of Composites Using Plate Waves

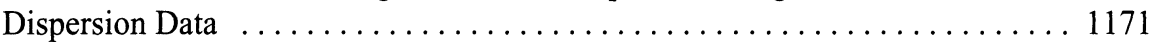

Y. Bar-Cohen, S-S. Lih, A. Mal, and Z. Chang

Parallel Computation of Ultrasonic Wave Propagation in Orthotropic Composite Materials ................................... 1177

R. S. Schechter, N. K. Batra, R. B. Mignogna, K. E. Simmonds, and

P. P. Delsanto

Nondestructive Holographic Interferometry Methods for the Dynamic Structural Analysis of a Graphite-Epoxy Polymer Composite Structure . . . . . . . . . 1185

H. Fein

Evaluation of the Interfacial Sliding Stress of Ceramic Matrix Composites under

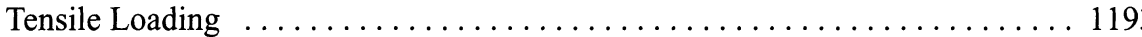

J.-M. Morvan and S. Baste

In-Situ Observation of the Stress Field of the Failure Process in Single Fibre

Reinforced Polymers

S. Ritter and G. Busse

Investigation of Thermal Diffusivity for Nano-Phase Composite Ceramics . . . . . . . 1209

F. Xiao, X. R. Zhang, D. Fei, C. M. Gan, G. H. Lei, D. Zhang, Y. P. Jin, and

G. D. Zhang

Simple Thermal Wave Method for the Determination of Longitudinal Thermal

Diffusivity of SiC-Based Fiber . . . . . . . . . . . . . . . . . . . 1217

M. Oksanen, R. Scholz, and L. Fabbri

Detection of Vertical Cracks in Carbon Fiber Composites Using an Infrared Line

Scanner ................................. 1223

J. Varis

Ultrasonic Backscatter Rotation Scanner for Detection of Ply Bends and Fiber

Wrinkles

L. H. Pearson, L. G. Porter, and G. A. Yurich

Ultrasonic Studies of Composites Undergoing Thermal and Fatigue Loading

E. I. Madaras, W. P. Winfree, and P. H. Johnston

Quantification of Damage Evolution in Multilayered High Temperature Composites from Ultrasonic Measurements

A. D. Degtyar and S. I. Rokhlin

Advanced Inspection of Thermal Protection Systems

J. O. Taylor 


\section{Section B. Coatings, Films, and Bond}

Characterization of Epoxy-Coated Oxide Films Using Acoustic Microscopy . . . . . 1261

B. D. Zeller, A. J. Kinloch, P. Cawley, P. Zinin, O. Lefeuvre, G.A.D. Briggs, G. E. Thompson, and X. Zhou

Investigation of Thin Layers Ceramic Structures Based on Doppler Scanning Acoustic Microscopy

S. A. Titov, R. G. Maev, and A. N. Bogachenkov

An Ultrasonic Method for Simultaneous Determination of Elastic Moduli, Density, Attenuation and Thickness of a Polymer Coating on a Foil

A. I. Lavrentyev and S. I. Rokhlin

Ultrasonic Characterization of Nickel-Chromium-Base Anticorrosive Coatings . . . 1285

V. F. Godínez-Azcuaga, M. A. Marcial-Amaro, J. Porcayo-Calderón, and O. Mayorga-Martín

Lamb Wave Imaging and V(Z) Using a Broadband System

N. Saffari and C.-S. Ong

Buried Thermoplastic Layer Diagnostics by the Use of Photo-Thermo-Acoustic Radiometry

M. Munidasa, A. Mandelis, and M. Ball

Efficient Eddy Current Models for Evaluation of Thin Conductive Coatings on Ferromagnetic Substrates . . . . . . . . . . . . . . . . . . . . 1307

B. de Halleux and A. Ptchelintsev

Brillouin Scattering as a Tool for Characterizing Surfaces, Interfaces and Thin Films 1315 W. Pang, A. G. Every, J. D. Comins, P. R. Stoddart, X. Zhang, J. C. Crowhurst, and D. Pietersen

Observation of Shear Wave Generation at Bonded Silicon-Carbide Interface

D. K. Rehbein, M. Akinc, J. Zheng, and O. Buck

Acousto-Ultrasonic Techniques for Evaluation of Bond Integrity of Composite

Repair Patches

I. M. Daniel, J.-J. Luo, and H.-M. Hsiao

The Ultrasonic Detection of Environmental Degradation in Adhesive Joints

K. Vine, P. Cawley, and A. J. Kinloch

An Ultrasonic Technique to Detect Nonlinear Behavior Related to Degradation of

Adhesive Bonds

Z. Tang, A. Cheng, and J. D. Achenbach

Ultrasonic Characterization of Thin Plate Bonding

Q. Xie, A. I. Larentyev, and S. I. Rokhlin

Ultrasonic Evaluation of Transient Liquid Phase Bonding in Single Crystal

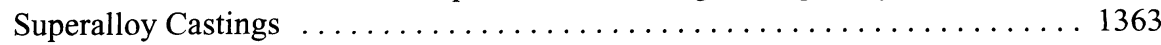

D. K. Hsu, J. J. Peters, R. Singh, P. D. Freyer, R. E. Shannon, and P. Zombo 
Microtopographic Inspection of Thermoplastic Rubber Shoe's Sole: The Influence of Surface Roughness on Sole to Leather Gluing . . . . . . . . . . . 1371

M. F. M. Costa, and V. Pinho

Ultrasonic Spectroscopy of Two Parallel Imperfect Interfaces . . . . . . . . . . . 1379

A. I. Lavrentyev, A. Baltazar, and S. I. Rokhlin

Imaging Flaws in Adhesive Joints Using Acoustic Techniques and Infrared Thermography ............................... 1387

D. Hopkins, S. Nakagawa, K. Nihei, and D. Turler

Nondestructive Testing System to Assess Lack-of-Bond in Brazed Generator Coils

by Ultrasonic Retro-Reflection

W. Hassan, P. B. Nagy, and J. F. Hopeck

Evaluation of Bonded Boron/Epoxy Repairs on Aircraft Skin with Simulated

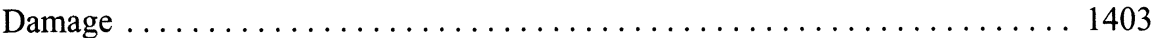

H. Aglan, Z. Zhang, T. Rowell, T. Ahmed, and R. Thomas

\section{CHAPTER 6. MATERIALS CHARACTERIZATION}

\section{Section A. Materials Properties}

Effects of Molecular Weight on Mechanical Properties of the Polyimide LaRC-Si ${ }^{\mathrm{TM}} \ldots 1411$ W. T. Yost, J. H. Cantrell, T. S. Gates, and K. S. Whitley

Laser-Ultrasonic Optical Characterization of Nonmetals

A. Hammoutene, F. Enguehard, and L. Bertrand

Numerical Solution of a Direct 3D Electrostatic Resistivity Test of Green-State Metal Powder Compacts ............................... 1427

S. Makarov, R. Ludwig, and D. Apelian

Characterization and Depth Profile of Lithium Depletion in Aluminum-Lithium

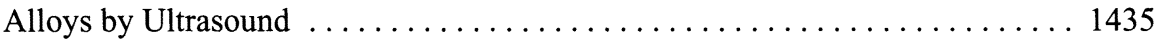

E. A. Lindgren, L. P. Martin, and M. Rosen

Structure and Deformation of Aluminum Foams through Computed Tomography . . 1443

D. J. Sypeck, H. N. G. Wadley, H. Bart-Smith, S. Koehler, and A. G. Evans

The Detection of Magnetic Phase Transitions in ER-TM by Electromagnetic Acoustic Transducers ............................... 1451

C. M. Lim, S. Dixon, C. Edwards, and S. B. Palmer

Investigation of Sound Property of Laser-Shocked Aluminum Alloy 1457

X. R. Zhang, Y. K. Zhang, and S. Y. Zhang

Detection of Hardness Variations of Steel through Stainless Steel 1465

J. T. Lovett, O. H. Zinke, and W. F. Schmidt

Ultrasonic Signal Attenuation in Engine Titanium Alloys 1469

F. J. Margetan, P. D. Panetta, and R. B. Thompson 
Finite Element Modeling of the Effect of Creep Damage on a Magnetic Detector

Signal for Seam-Welded Steel Pipes ............................ 1493

M. J. Sablik, D. C. Jiles, and M. R. Govindaraju

Thickness Evaluation for Steel Sheets Using Saturation Magnetization 1501

G. H. Shirkoohi and J. Z. Cao

Detection of Fatigue Crack Propagation in Steel Using Magnetic Measurements ... 1509 Y. Bi and D. C. Jiles

Ultrasonic Imaging of Spall Damage under Repeated Plate Impact Tests with C-scan

Acoustic Microscope

K. Kawashima, N. Nishiura, M. Takano, and O. Nakayama

Acoustic Microscopy Inspection of Glass Repair Techniques

J. Johnson

\section{Section B. Construction Materials}

A Formalism for Acoustical Traveltime Tomography in Heterogeneous Anisotropic Media ........................................... 1529

L. Song, S. Zhang, H. Liu, S. Chun, and Z. Song

Ultrasonic Wave Dispersion and Attenuation in Fluid Filled Porous Media

H. Tavossi, B. R. Tittmann, and F. Cohen-Tenoudji

Characterization of Rayleigh Wave Propagation in Concrete Using Laser

Ultrasonics ........................................ 1545

J. O. Owino and L. J. Jacobs

Acoustic Inspection of Bond Strength between Mortar and Reinforcement ....... 1551

C.-H. Chiang, Y.-C. Kan, C.-K. Tang, and C.-S. Su

Guided Ultrasonic Waves for the Inspection of Post-Tensioned Bridges

B. Pavlakovic, M. Lowe, and P. Cawley

Defect Visualization and Location of Reinforcing Bars and Cables in Concrete

Using Active Electromagnetic Induction Imaging . .

J. L. Simmonds and P. A. Gaydecki

\section{Section C. Fracture and Cracks}

Thermo-Electric Detection of Early Fatigue Damage in Metals 1573

P. B. Nagy and J. Hu

Acoustic, Electron and Optical Microscopy Visualization of Surface and

Sub-Surface Cracks

Z. M. Connor, M. E. Fine, and J. D. Achenbach 
K. I. McRae and R. W. Nolan

Characterization of the Fatigue Behavior of Austenitic Steel Using HTSL-SQUID . 1597 H.-J. Bassler, D. Eifler, M. Lang, and G. Dobmann

Ultrasonic Characterization of Fatigue Damage in Metal Matrix Composites . . . . . 1605

S. I. Rokhlin, M. Ganor, and A. D. Degtyar

Assessment of the Crack System Orientations of a Ceramic Matrix Composite under

Off-Axis Tensile Loading . . . . . . . . . . . . . . . . . . . . 1613

S. Baste and C. Artistégui

\section{Section D. Stress/Texture}

Stress State Evaluation of Laminated Aluminum Alloy Sheets by Surface Acoustic Waves .......................................... 1621

M. Duquennoy, M. Ouaftouh, M. Ourak, and L. Camus

Dynamic Stress Distribution in Unidirectionally Undulated Fibrous Composites . . . 1627

W. G. Abdelrahman and A. H. Nayfeh

Effects of Residual Stress on Guided Waves in Layered Media . . . . . . . . . . 1635

J. Qu and G. Liu

Measurement of Acoustoelastic Effect of Rayleigh Surface Waves Using Laser

Ultrasonics

W.-Y. Lu, L. W. Peng, and S. Holland

Attenuation and Dispersion of Ultrasonic Waves in Rolled Aluminum 1649

S. Ahmed and R. B. Thompson

Extension of Ahmed \& Thompson Theory to General Elastic Plane Quasi-Wave

Propagation in Textured Polycrystalline Material

V. K. Munikoti and A. W. Eberhard Neumann

\section{CHAPTER 7. NEW INSPECTION/CONTROL PROCEDURES}

\section{Section A. New Techniques}

Thickness Measurements of Curved Multi-Layered Polymer System Using

Ultrasonic Pulse-Echo Method . . . . . . . . . . . . . . . . . . . . . . . . . . . 1665

R. G. Maev, H. Shao, E. Y. Maeva

Simultaneous Determination of Orientation and Thickness in Anisotropic Media . . 1673 R. A. Kline, J. B. Deaton, and D. R. Howard

High-Speed Monitoring of Surface Defects in Rail Tracks Using Ultrasonic Doppler

Effect . . . . . . . . . . . . . . . . . . . . . . . . . . . . . . . . . . 1681

S.-C. Wooh and A. Clay 
NDT of Specimen of Complex Geometry Using Ultrasonic Adaptive

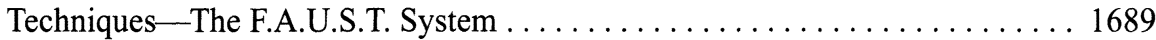

O. Roy, S. Mahaut, and M. Serre

Self-Focusing of Rayleigh Waves: Simulation and Experiment

W.A.K. Deutsch, A. Cheng, and J. D. Achenbach

Numerical Simulation of Self-Focusing of an Array on an Interior Crack

M. Zhang and J. D. Achenbach

A Novel High Speed, High Resolution, Ultrasound Imaging System

M. Lasser

Ultrasonic Wave Propagation in a Tooth Phantom

S. R. Ghorayeb, T. Xue, and W. Lord

Wide-Area Imaging of Ultrasonic Fields by Digital Phase-Stepping Shearography . . 1729

G. A. Gordon, B. A. Bard, and S. Wu

Spatial Resolution with Time-and-Polarization-Resolved Acoustic Microscopy . . . . 1737

D. Xiang, N. N. Hsu, S. E. Fick, and G. V. Blessing

Time-Resolved Line Focus Acoustic Microscopy Using Lamb Waves for Material

Characterization of Thin Plates . . . . . . . . . . . . . . . . 1745

J. Vollmann, A. Cheng, and J. D. Achenbach

Photoinductive Imaging for Bolt Hole Corner Crack Inspection

C.-C. Tai and J. C. Moulder

D2D: A Robust Technique for Detection of Structural Heterogeneities in Solids,

Based on Transient Thermography

A. Braggiotti, S. Marinetti, and A. Mazzoldi

Fresco Thermographic Inspection by Convective Heating Technique . . . . . . . 1769

P. G. Bison, E. Grinzato, S. Marinetti, and A. Braggiotti

Response of Laser-Induced Thermal Lens Effect at Solid Surface

J. Fang and S. Zhang

High-Speed High-Resolution Subsurface Defect Detection in Ceramics Using

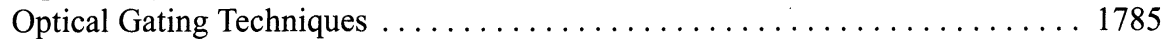

M. Bashkansky, M. D. Duncan, and J. Reintjes

Non-invasive Measurement of Prepreg Resin Content Using Nuclear Magnetic

Resonance .................................... 1793

G. A. Barrall, P. V. Czipott, E. E. Magnuson, C. R. Moeller, and S. M. Menon

A Study on the Measurement of In-Plane Displacement at High Temperature by

Electronic Speckle Pattern Interferometry Method . . . . . . . . . . . . . 1801

K.-S. Kim, H.-T. Kim, Y.-H. Cha, H.-C. Jung, S.-S. Jarng, J.-Y. Kim, and

S.-P. Yang

Recent Advances and Implementations of Flexible Eddy Current Probe Technology . 1809

R. J. Filkins, J. P. Fulton, T. C. Patton, and J. D. Young 
H. T. Banks and P. Emeric

Refining Automated Ultrasonic Inspections with Simulation Models 1825

M. Garton

Saw-Cut Scanning Patterns

W. F. Schmidt and O. H. Zinke

\section{Section B. Process Modeling/Control}

Modeling of Microporosity Evolution during Solidification Processes 1839

J. Huang and J. G. Conley

Coupling Microstructure Outputs of Process Models to Ultrasonic Inspectability Predictions .................................... 1847

R. B. Thompson, F. J. Margetan, I. Yalda, C. P. Chiou, and P. Panetta

A Formalism for Predicting Ultrasonic Properties of Alloys in a Semi-Solid State . . 1855 A. F. Niessner III and G. A. Gordon

Model Based Predictive Control for the Tow-Placement Technique 1863

D. Heider and J. W. Gillespie, Jr.

A Study on Characteristics of Echoes from Planar Defects by the Ultrasonic Testing of Angle Beam Technique .............................. . 1869

H. Shirahata and C. Miki

Defect Detection in Copper Products with an Infrared Line Scanner

J. Varis

Development of On-Line NDE for the Continuous Resin Transfer Molding

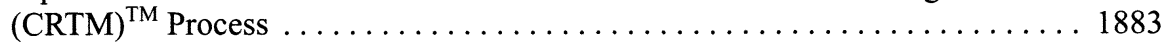

R. W. Engelbart and D. D. Palmer

Ultrasonic Measurement of Clearances of a Rolling-Piston Type Rotary Compressor 1891 N. Kim and J. Kim

Ultrasonic Monitoring of Recrystallization Textures in Aluminum 1899

G. Liu, F. Laabs, D. Rehbein, O. Buck, and R. B. Thompson

\section{CHAPTER 8. SYSTEMS, RELIABILITY, TRAINING}

\section{Section A. New Systems}

A Non-Contact Laser-Emat System for Crack and Hole Detection in Metal Plates . . 1907 S. Dixon, C. Edwards, and S. B. Palmer

A New Automated System for Boreside Ultrasonic Inspection of Power Plant Turbine Rotors . . . . . . . . . . . . . . . . . . . . . . . . . . . . 1915 M. Ley-Koo, V. F. Godinez-Azcuaga, M. A. Marcial-Amaro, A. Aguilar-Soto, and S. Salazar-Cruz

Field and Beta-Site Testing of the Dripless Bubbler Ultrasonic Scanner . . . . . . . 1921

D. J. Barnard and D. K. Hsu 
A Novel Non-Contact Ultrasonic System for Liquid Level Measurement in Moving

Metallic Containers .................................. 1929

S. Dixon, C. Edwards, and S. B. Palmer

Adaptive Heterodyne Interferometer for Ultrasonic NDE

B. F. Pouet, R. K. Ing, S. Krishnaswamy, and D. Royer

Inspection of Flip-Chip Epoxy Underfill in Microelectronic Assemblies Using

Compensated Laser-Based Ultrasonic Receivers . . . . . . . . . . . . . . . . . . 1943

D. M. Pepper, G. J. Dunning, M. P. Chiao, T. R. O’Meara, and P. V. Mitchell

Digital Measuring Borescope System

G. McGarry

Detection of Open Cracks by a Photothermal Camera

L. Legrandjacques, J. C. Krapez, F. Lepoutre, and D. L. Balageas

An Adaptive Morphological Filter for Defect Detection in Eddy Current Aircraft

Wheel Inspection

S. Gao and L. Udpa

Integrated Quality Assurance Program for the Hydra-70 Solid Rocket Motor

E. Morris, L. M. Glowacki, and L. J. Bond

CEA Program for Multiple-Technique Non-Destructive Testing: The CIVA System .. 1981

L. Paradis, M. Talvard, P. Benoist, P. Rizo, G. Pascal, and G. Bayon

Versatile Robotic Instruments for NDT/NDE Data Acquisition

B. Bridge, T. Sattar, A. Khalid, S. Chen, M. Rakocevic, and X. Wang

Complex Contour Ultrasonic Scanning System Application and Training

S. J. Wormley and H. Zhang

\section{Section B. System Reliability}

POD Assessment Using Real Aircraft Engine Components

A. Fahr and D. S. Forsyth

The Application of a Dynamic Threshold to C-Scan Images with Variable Noise . . . 2013

P. J. Howard, D. C. Copley, and R. S. Gilmore

A Comparison of the Ability of Phase-Insensitive and Phase-Sensitive Ultrasonic

Receivers to Detect Material Abnormalities beneath Rough Surfaces . . . . . . 2021

K. W. Hollman, R. L. Trousil, M. R. Holland, and J. G. Miller

An Experimental Evaluation of the Resonant Ultrasonic Spectroscopy Method . . . . 2029

M. C. Renken, C. M. Fortunko, K. W. Hollman, and S. Kim

Ultrasonic C-Scan Standardization for Polymer-Matrix Composites-Acoustic

Considerations

R. A. Smith, D. A. Bruce, L. D. Jones, A. B. Marriott, L. P. Scudder, and

S. J. Willsher

Probability of Detection Modeling for Ultrasonic Testing 2045

P. Sarkar, W. Q. Meeker, R. B. Thompson, T. A. Gray, and W. Junker 
Improved Methodology for Inspection Reliability Assessment for Detecting

Synthetic Hard Alpha Inclusions in Titanium

W. Q. Meeker, S.-L. Jeng, C.-P. Chiou, R. B. Thompson

The Use of Ultrasonic Flaw and Noise Models in Designing Titanium Test Blocks . . 2069

C.-P. Chiou, I. Yalda, F. J. Margetan, R. B. Thompson, and D. J. Sturges

\section{Section C. Training}

North Central Collaboration for Education in NDE/NDT 2077

B. Larson and D. Holger

Technology Transfer Using XRSIM as a Training Tool

B. Crouse, J. Gray, and B. Larson

Internet Offering to Foster NDE/NDT Technological Education in Community and Technical Colleges

S. J. Wormley

Attendees

Contributors Index 2115

Subject Index 2123 